Claude MAZAURIC, Jean-Jacques Rousseau à vingt ans, un impétueux désir de liberté

Vauvert, Au diable vauvert, 2011, 168 p., ISBN 978-2-84626-298-9, $12 €$.

\title{
Stéphanie Roza
}

\section{(2) OpenEdition}

1 Journals

Édition électronique

URL : https://journals.openedition.org/ahrf/12898

DOI : $10.4000 /$ ahrf. 12898

ISSN : 1952-403X

Éditeur :

Armand Colin, Société des études robespierristes

\section{Édition imprimée}

Date de publication : 1 septembre 2013

Pagination : 215-217

ISBN : 9782200928261

ISSN : 0003-4436

\section{Référence électronique}

Stéphanie Roza, "Claude mazauric, Jean-Jacques Rousseau à vingt ans, un impétueux désir de liberté », Annales historiques de la Révolution française [En ligne], 373 | juillet-septembre 2013, mis en ligne le 03 octobre 2013, consulté le 01 juillet 2021. URL : http://journals.openedition.org/ahrf/12898; DOI : https://doi.org/10.4000/ahrf.12898

Ce document a été généré automatiquement le 1 juillet 2021.

Tous droits réservés 


\title{
Claude MAZAURIC, Jean-Jacques Rousseau à vingt ans, un impétueux désir de liberté
}

Vauvert, Au diable vauvert, 2011, 168 p., ISBN 978-2-84626-298-9, $12 €$.

\author{
Stéphanie Roza
}

\section{RÉFÉRENCE}

Claude MAZAURIC, Jean-Jacques Rousseau à vingt ans, un impétueux désir de liberté. Vauvert, Au diable vauvert, 2011, 168 p., ISBN 978-2-84626-298-9, $12 €$.

$1 \quad$ L'objet de l'ouvrage de Claude Mazauric est aussi clair que séduisant : à travers le récit de la jeunesse de Jean-Jacques Rousseau, jeunesse quelque peu prolongée, puisque nous ne le quittons que dans sa trente-deuxième année, il s'agit de rechercher les origines du génie philosophique et littéraire qui ne commença à se manifester véritablement qu'après cette période. Période de formation, assurément, celle d'un penseur tardif, dont les hésitations, les tentatives successives, les errances ne s'avérèrent fécondes qu'après-coup, dans le temps de la maturité, et sur un mode qu'elles ne laissaient pas vraiment pressentir. Pour Claude Mazauric, l'enjeu était donc double : d'une part, restituer pour un lecteur profane le contexte historique, à la fois social, politique, et intellectuel dans lequel le Jean-Jacques « d'avant les livres » évolue et devient peu à peu lui-même ; d'autre part, laisser deviner, aux yeux du nouveau venu dans l'univers rousseauiste, ce qui fut décisif dans cette formation de soi. Un pari réussi, et tout d'abord, quant à la précision, jamais trop didactique, avec laquelle la Genève républicaine, le royaume du Piémont-Sardaigne, qui s'étendait à l'époque jusqu'en Savoie, Lyon et Paris, sont évoqués avec leurs institutions, leurs particularités religieuses, et plus largement leurs pratiques sociales ; un pari réussi, également, quant au détail avec lequel la psychologie du jeune homme, et celle de ses proches, nous devient familière au fil des pages. 
2 L'enfance genevoise de l'auteur du Contrat social nous est donc présentée avec son drame fondateur, la mort en couches de sa mère, puis ses rebondissements successifs. D'abord confié à la garde de son père, Isaac Rousseau, descendant fantasque d'une famille de bourgeois calvinistes marquée par son attachement précoce aux institutions républicaines, l'enfant est très tôt familiarisé par ce dernier à la lecture des grands textes de l'Antiquité, ainsi qu'à des rudiments de latin, d'arithmétique, de cosmologie. Mais alors que Jean-Jacques atteint sa dixième année, son père est obligé de fuir Genève pour échapper aux suites d'une altercation avec un grand personnage lors de laquelle, fait notable, il a refusé de s'incliner. L'enfant est alors recueilli par le pasteur de Bossey, Jean-Jacques Lambercier, et sa soeur ; puis il revient à Genève, à treize ans, pour être mis en apprentissage chez un graveur. À dix-sept ans, la peur d'être puni après une incartade l'amène à fuir la cité calviniste : Jean-Jacques a définitivement quitté sa ville natale, qui n'existera pour ainsi dire plus pour lui que comme référence quasimythique, paradigme livresque d'une République peu conforme à son modèle.

3 Commence alors le temps de l'errance, là aussi, fondatrice de la personnalité de Rousseau. Recueilli par un curé des environs de Genève, Rousseau se convertit au catholicisme, et ce faisant, est amené à faire une rencontre décisive : celle de Mme de Warrens, apostate elle aussi, chez qui il séjournera de nombreuses années malgré les séparations sporadiques. Mère de substitution, initiatrice à bien des égards, cette surprenante aventurière conservera toujours la reconnaissance de Jean-Jacques. Cependant, la nécessité de parfaire la formation catholique du jeune homme d'abord, puis celle de se trouver une situation, l'éloignent à de nombreuses reprises d'une bienfaitrice auprès de laquelle il revient à chaque nouvel échec. C'est d'abord Turin, puis le séminaire d'Annecy, puis Lyon d'où il s'enfuit presque pour retrouver sa protectrice. De retour à Annecy, ne l'y trouvant plus, il est à nouveau entraîné dans des pérégrinations rocambolesques : ainsi, "c'est en marchant à travers la Savoie, le Piémont, la Suisse romande et la France orientale, que Jean-Jacques Rousseau est devenu adulte ». Par la suite seulement, entre 1731 et 1740 , il se stabilise auprès de Mme de Warens : vient le temps du refuge aux « Charmettes » où il parfait sa formation intellectuelle, musicale, affective aussi. Ce n'est qu'après que la relation avec cette dernière se sera considérablement distendue, que le jeune homme déjà âgé de 28 ans, décidera de gagner à nouveau Lyon, pour une carrière de précepteur bientôt avortée ; en 1742, il s'enfuira encore, dans la capitale cette fois-ci. De là, quelques tentatives professionnelles supplémentaires, toutes sans lendemain : dans la musique, dans la diplomatie internationale auprès de l'ambassadeur de Venise : enfin, à l'issue de toutes ces pérégrinations, riche d'une incroyable expérience sur le plan intellectuel, social et humain, Jean-Jacques est sur le point de devenir Rousseau. Ici s'achève le petit ouvrage.

De ces aventures, truculentes à plus d'un titre, on pouvait faire un récit quasiment romanesque ; et c'est un plaisir auquel Claude Mazauric n'a pas résisté, pour l'agrément indéniable du lecteur. Mais l'auteur n'a pas manqué non plus d'esquisser, au fil du texte, des pistes pour retracer la genèse de certaines des thèses plus tard fondamentales dans la pensée de Rousseau : de sa conception de la femme, qui continue de susciter le débat ; de sa vision de l'enfance et de l'éducation, à propos de laquelle Claude Mazauric montre bien en quoi elle peut être comprise comme une entreprise de salvation par la théorie des échecs de la pratique ; de ses positions politiques, enfin, qui après l'épisode vénitien s'aventurent rarement jusqu'à l'engagement direct, mais qui ne 
demeurent jamais indifférentes ni à la conjoncture ni aux potentialités de réforme que celle-ci renferme.

$5 \quad$ Une excellente entrée en rousseauisme. 